\title{
MFE/ACT: A TRS-80 Code for Calculating Neutron Activation
}

\begin{abstract}
The MFE/ACT code, written to run on the TRS-80, can be used to calculate the neutron activation of materials used in fission and fusion reactors. Input data include the specific isotopes to be calculated, the neutron fluxes, the neutron cross sections, ard the nuclear decay huif-iivis.
\end{abstract}

\section{Introduction}

As fusion research moves closer to engineering development and conceptual designs for fusion reactors emerge, it becomes increasingly clear that fusion power systems could generate large quantities of radioactive materials. ${ }^{1-10}$ This radioactivity is the normal result of the absorption of neutrons given off in the deuterium-deuterium (D-D) and deuterium-tritium (D-T) fusion reactions and the consequent transmutation of elements in the structura! steels and other materials in the reactor. Currently, most of the design effort in fusion is devoted to reactors using the $D-T$ reaction; thus, there are both low- and highenergy neutrons. To design reactors that minimize the radioactivity, one must understand how these neutrons interact vrith the structural components and the subsequent decay of the induced radioactivity.

While a number of sophisticated neutron-activation codes already exist, ${ }^{11,12}$ a relatively simple and accessible code is needed so that one can quickiy petform rough calculations of neutron-activation products when the materials and operating conditions in fusion reactors change. The code developed to meet this need is MFE/ACT. MFE/ACT is desigred to run, in interactive mode, on Radio Shack's TRS-80, Model Ill. All data are input from the keyboard, or taken from disk in response to prompts from the code.

MFE/ACT is not designed to replace the more sophisticated and complete codes, ${ }^{1,12}$ but morely to allow the user freedom to rapjdly vary any and all data and operating parameters, Once a problem has been identified using this code, it is expected that the user will do a more complete study using all the calculational toois available. For example, since the code was originally developed to study long-term waste-disposal problems, it focuses on long half-lived isotopes and does not treat short-lived isotopes as well.

\section{The Model}

The model used is a stepwise integration of the differential equation goveming the growth and loss of each specific isotope. Data are needed for the major neutron-induced reactions and for the major radioactive decay modes. The reactions and decay modes considered are shown in Table 1.

Table 1. Major reactions.

Neutron induced

n,gamma

n,2n

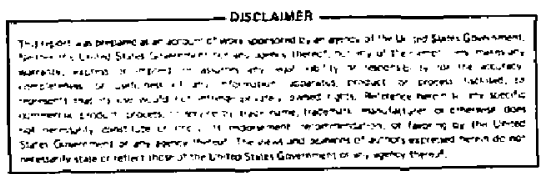

n, 3n

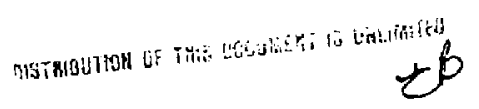




$n, p$
$n, n^{\prime} \mathbf{p}$
$n, a l p h a$
$n, n^{\prime} a l p h a$
$n, d$
$n, n^{\prime} d$
$n, t$
Radioactive decays
alpha decay
beta decay
positron decay
electron capture

The buildup and decay of a specific isotope, $N(z, n)$, can then be found from:

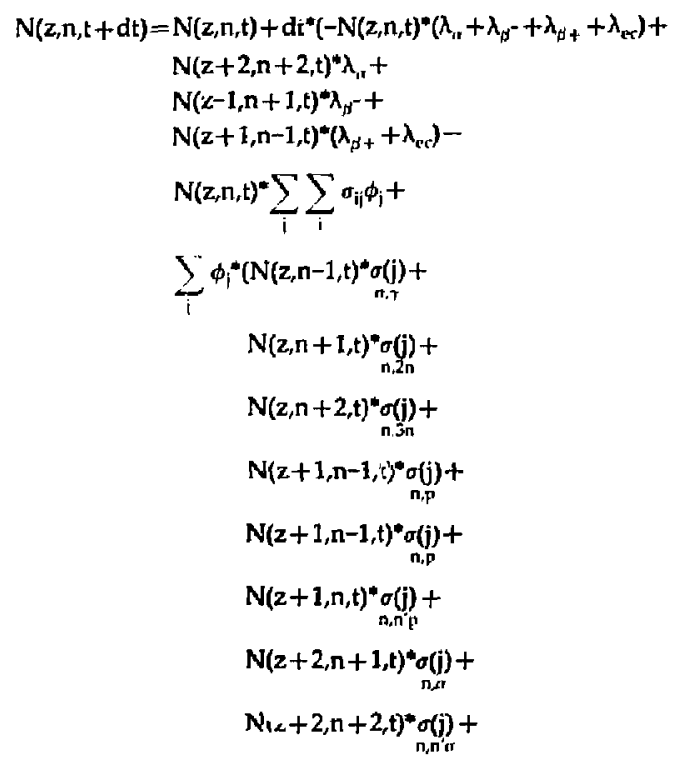




$$
\begin{aligned}
& \mathrm{N}\left(2+1, \mathrm{n}, \mathrm{t}^{*} \sigma(\mathrm{j})+\right. \\
& \mathrm{N}(\mathrm{z}+1, \mathrm{n}+1, \mathrm{t})^{*} \sigma(\mathrm{j})+ \\
& \mathrm{N}(\mathrm{z}+1, \mathrm{n}+1, \mathrm{t}) * \sigma(\mathrm{j}))),
\end{aligned}
$$

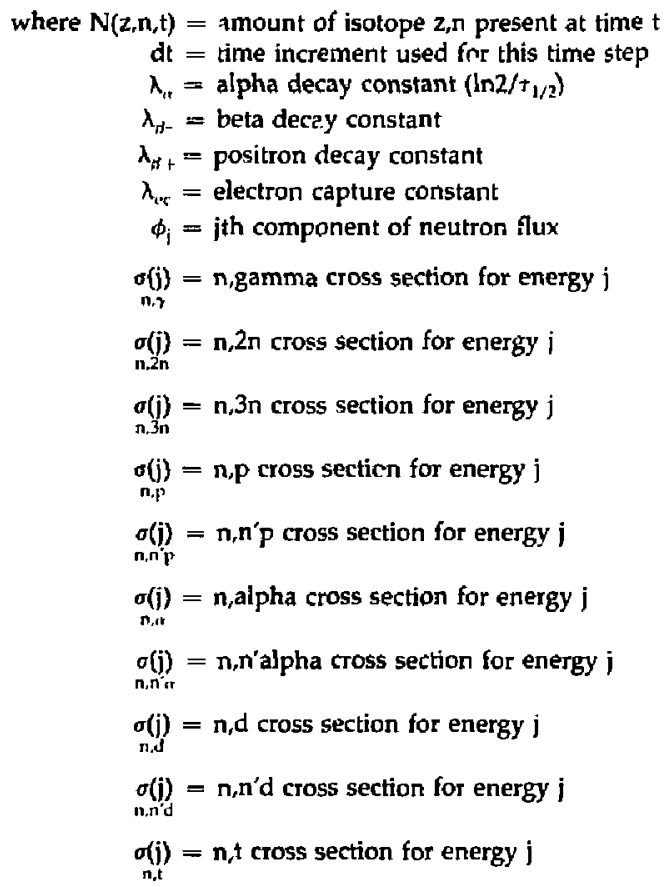

The energy-dependent neutron flux is obtaineu from one of several standard neutronics codes (e.g. TARTNP, ONEDANT). The cross sections are averaged over the neutron flux:

$$
\begin{gathered}
\sigma_{\text {slow }}=\frac{\int_{0}^{1} \sigma(\mathrm{E}) \phi(\mathrm{E}) \mathrm{dE}}{\int_{0}^{1} \phi(\mathrm{E}) \mathrm{dE}} \\
\sigma_{\text {fast }}=\frac{\int_{1}^{15} \sigma(\mathrm{E}) \phi(\mathrm{E}) \mathrm{dE}}{\int_{1}^{15} \phi(\mathrm{E}) \mathrm{dE}}
\end{gathered}
$$


Neutron fluxes and cross sections are assumed to be constant both over the time of calculation and in space. Thus, the calculation gives specific activities at a given point, not the average over a complete component.

The neutron cross sections used to date in the averaging are from the ACTL library ${ }^{13}$ maintained by Howerton. Where little or no data are available (e.g., for strontium and technecium), systertatics observable in the data for similar isotopes can be extencied to the unknown isotopes. The radioactive half-lives are taken from the Table of Isotopes. ${ }^{14}$ Other data sources can readily be used.

The time increment, $\mathrm{dt}$, is calculated each calculational cycle so any isotope in the calculational grid that is greates than $1 \%$ of the initial source loading does not change by more than the percentage change specified. The calculation of $\mathrm{dt}$ is also constrained by two additional requirements: that it not change by more than a factor of two in a time step, and that jt not fall below 0.05 year or grow larger than 2 years. It decay rates or transmutation rates should, because of the size of the time increment, cause the amount of an isotope to become negative, the rates for that isotope are adjusted. Specifically, all rates for that particular isotope and time step are scaled for that time step to allow the amount of isotope to fall to, but not below, zero. In practice, this seems to allow reasonable time steps while preserving the overalt features of the transmutation calculations.

\section{The Code}

Figure 1 illustrates the various reactions treated in MFE/ACT, along with the parent/daughter relationships. Neutron-induced reactions and radioactive decays for each isotope in the grid are calculated for each time step. The grid covers isotopes from atomic number $z-2$ to $z+1$ and from neutron number $A(\min )-z-2$ to $A(\max )-z+2$, where $z$ is the atomic number of the parent element being exposed to the neutron flux and $A(\min )$ and $A(\max )$ are the minimum and maximum mass numbers for stable isotopes of that element. Losses from isotopes withis the grid to isotopes outside the grid are calculaied and subtracted from within the grid, but are not tallied. A listing of the code appears in the Appendix.

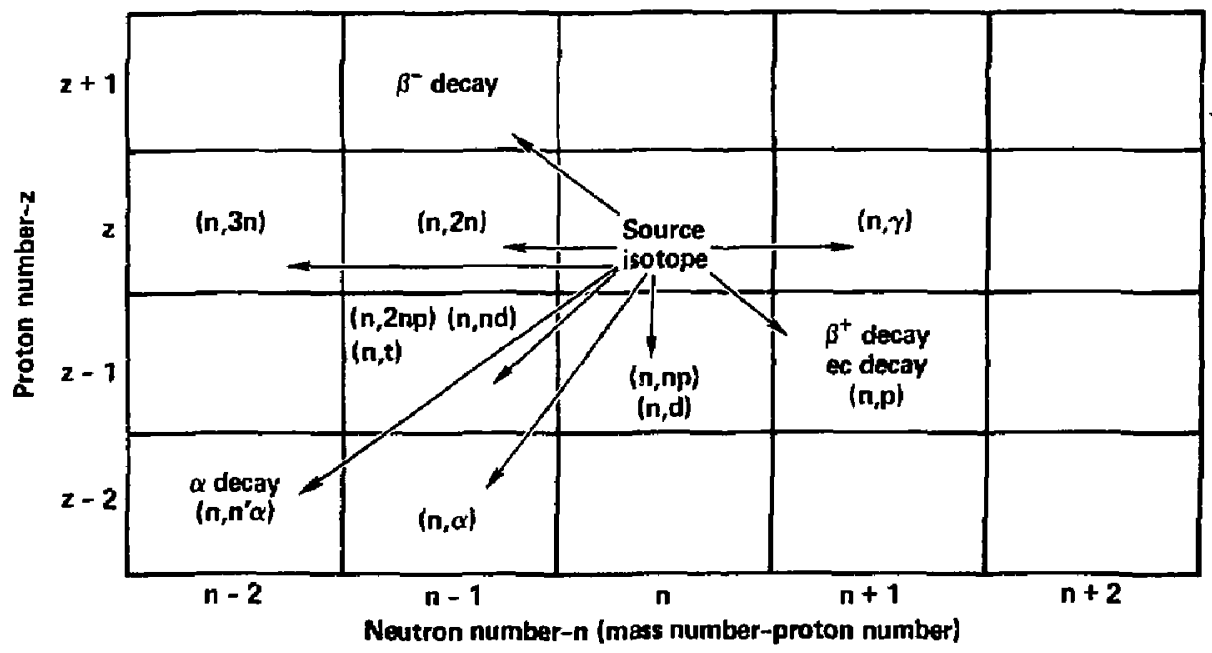

Figure 1. Typical calculational matrix for source isolope. 


\section{Code Operation}

The name of the code on disk is "MFE/ACT." To begin, one must first load the TRS-80 BASIC and then MFE/ACT. When RUN is typed, the code responds with a list of eight "FUNCTIONS." After the user has selected one of these eight functions, the code executes the function selected.

1. SELECT SOURCE - sets the initial parameters needed to size the calculational grid.

2. READ HALF LIFE AND CROSS SECTION DATA FROM DISK-fills the calculational grid with the nuclear data needed for subsequent calculations.

3. ENTER/CHANGE RADIOACTIVE DECAY DATA-allows the user to change the nuclear data read from the disk (in function 2), or to enter new data as appropriate.

4. ENTER/CHANGE NEUTRON CROSS SECTION DATA-allows the usex, as with function 3, to change the data read or to enter new data.

5. SAVE HALF LIFE AND CROSS SECTION DATA UIN DISK-creates a neי, disk file, or overwrites an old one, to save the nuclear data entered.

6. SET INITIAL PROBLEM CONDITIONS AND RUN PROBLEMS-allows the user to set the parameters needed to calculate a particular problem.

7. MAP DATA FROM ONE DISK FILE TO ANOTHER-allows the user to create a new nuclear data file, in part, by copying portions of an existing file that has data needed for the new file. (Since many of the isotopes required to create the calculational grid for iron and nickel are common to both, one could, for example, copy appropriate data from an existing file for iron into a new disk file for nickel, thereby reducing the new input data seeded.)

8. END SESSION-returns control to the user, with the TRS-80 in BASIC.

Input

All input data are given in response to prompts from the code, as the following examples illustrate. When any operation listed in "FUNCTIONS" is completed, control is retumed to the user, who can then select another operation. Since information on the element being considered is required for several possible operations, the user may have to select function 1 (SELECT SOURCE) before proceeding. If such information is required, a separate prompt will so indicate. Also, since data are ordinarily read from the disk, function 2 is usually required before function 6 is executed.

Sample Input

MFE ACTIVATION CALCULATION, D.W. DORN 1982

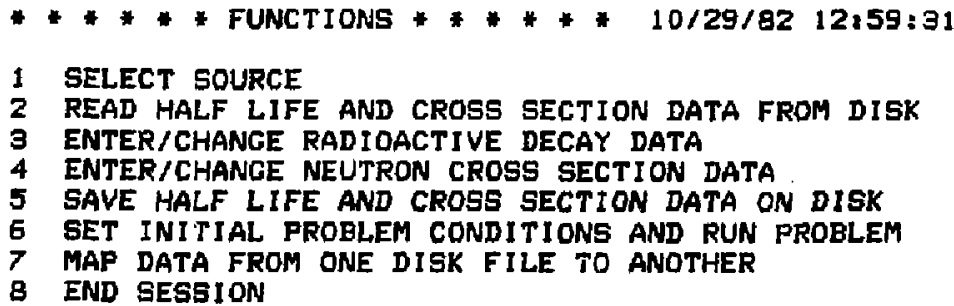


SELECT DESIRED FUNCTION? I

WHAT IS THE MATERIAL YOU WILL BE CALCULATING AND WHAT IS ITS

ATOMIC NUMBER (Z)? NI, 2B

HOW MANY ISOTOPES WILL YOU BE CALCULATING? 5

WHAT IS THE MASS NUMBER DF ISOTOPE I AND WHAT IS ITS

7 ABUNDANCE? 58,67,76

WHAT IS THE MASS NUMBER DF ISOTOPE 2 AND WHAT IS ITS

* ABUNDANCE? $26.60,26.16$

WHAT IS THE MASS NUMBER OF ISOTOPE 3 AND WHAT IS ITS

$\times$ AELUNDANCE? $61,1.25$

WHAT IS THE MASS NUMEER OF ISOTOPE 4 AND WHAT IS ITS

* ABUNDANCE? 62, 3.66

WHAT IS THE MASS NUMBER OF ISOTOPE 5 AND WHAT IS ITS

* AEUNDANCE? $64,1.17$

WHAT IS THE AMOUNT OF NI, IN UNITS OF NUCLEI/MB? 1EZB

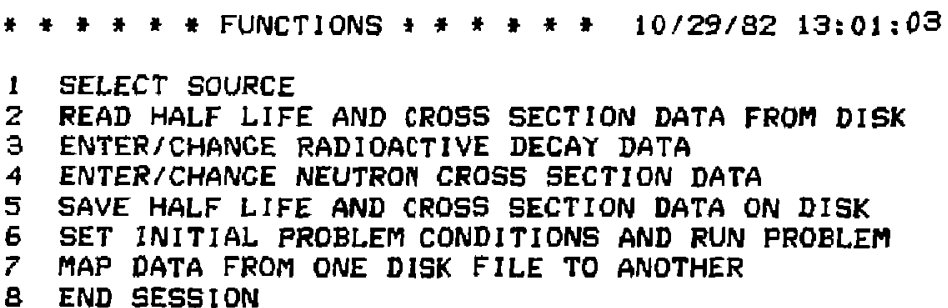

SELECT DESIRED FUNCTION? 2

WHAT IS THE NAME OF THE DISK FILE? NIMARFW

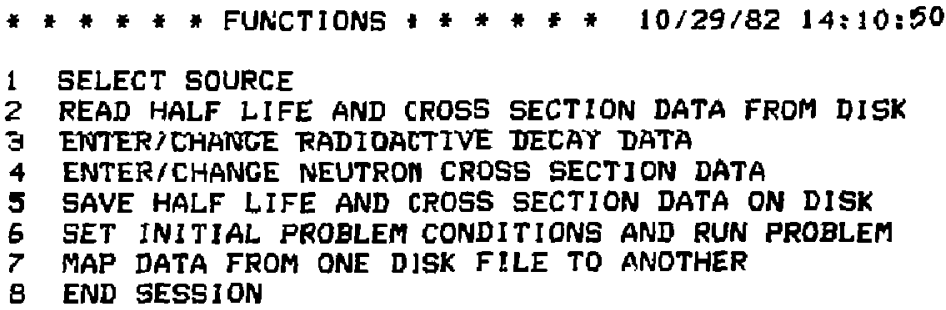

SELECT DESIRED FUNCTLON? 6

WHAT IS THE NAME OF THIS PROBLEM? NICKEL - MARS FIRST WALL

WHAT ARE FLUXES FOR THE FAST AND SLOW NEUTRONS (UNITS OF $1 E 18 \mathrm{~N} /$ M2-SEC)? $3.57,26.6$

WHAT 15 THE CUTOFF TIME FOR THE FLUXES (YRI? 5

WHAT PERCENTAGE CHANGE WILL YOU ALLOW FOR AN ISOTOPE IN ONE TIME STEP? 5

HOW FREQUENTLY DO YOU WANT AN EDIT (YR)? 1 


\section{Output}

Output from the code consists of a series of edits giving both the number density and specific activity of the calculated isotopes. The output also gives the total radioactivity at 1 hour, 1 day, 1 week, 30 days, and 1 year and at 5,10,20,50,100,1,000, and 10,000 years after the reactor is shut down or the structural component is removed from the neutron flux. In addition, it gives the five major radioactive isotopes and their activity at each of these times, as well as a summary of the input data and the date and time the problem was run. While the code is calculating a problem, a display on the screen allows the operator to track the calculations. This display shows the probiem time (total elapsed time in years), the time increment currently in use, and the particular grid point that is controlling the time increment. The grid is updated each cycle during the calculation.

\section{Sample Display}

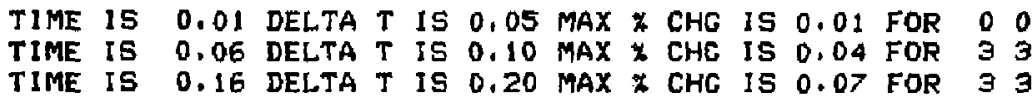

NICKEL - MARS FIRST WALL

THIS IS THE Z,N MAP (NUCLEI/MG) FOR NI FOR TIME= 0,0 YR. $\begin{array}{lllllll}28 & 29 & 30 & 31 & 32 & 33 & 34\end{array}$

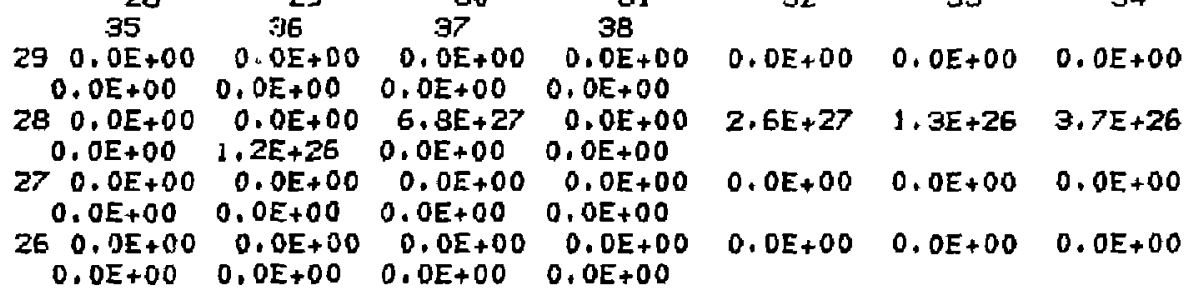

THIS IS THE Z, N MAP SHOWING ACTIVITIES IN CURIES/MB

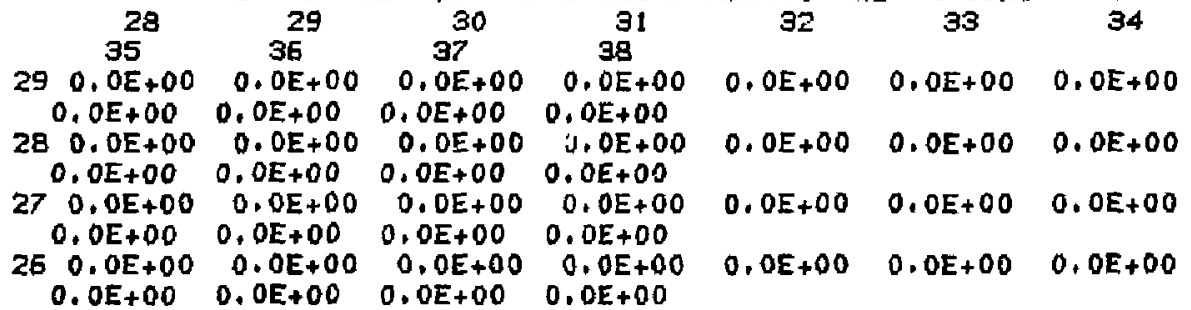

ALPHAS ACCUMULATED $=0,0 E+00$ (PARTS PER MILLION)

HYDROGEN ACCUMULATED $=0.0 E+00$ (PARTS PER MILLION)

DEUTERIUM ACCUMULATED $=0.0 E+00$ (PARTS PER MILLION)

TRITIUM ACCUMULATED $=0,0 E+00$ (PARTS PER MILLION)

THE $\star$ OF NI TRANGMUTED IS 0.00 
IT WAS CHANGED INTO

$0.00 \times Z=26$

$0.00 * Z=27$

$0.00 \times 2=29$

This initial output is followed by subsequent edits at the interval specified by the user under function 6. Folkiwing is an example of the last edit requested.

NICKEL - MARS FIRST WALL

$\begin{array}{ccccccc}\text { THIS IS THE Z,N MAP (NUCLEI/MG) FOR NI FOR TIME } & =5,0 \text { YR. } \\ 2 B & 29 & 30 & 31 & 32 & 33 & 34\end{array}$

$35 \quad 36 \quad 37 \quad 38$

$29 \quad 0.0 E+00 \quad 0.0 E+00 \quad 0.0 E+00 \quad 0.0 E+00 \quad 2.8 E+09 \quad 3.7 E+15 \quad 1.2 E+23$

$5.2 E+18 \quad 6,0 E+23 \quad 3.5 E+16 \quad 3,0 E+11$

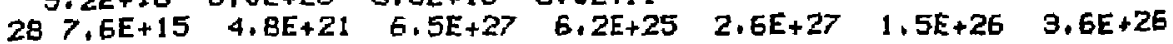

$7.8 E+24 \quad 1.1 E+2 E \quad 7.0 E+19 \quad 3.0 E+15$

$270.0 E+00 \quad 4.5 E+21 \quad 1.7 E+25 \quad 3.4 E+24 \quad 6.5 E+24 \quad 6.4 E+24 \quad 3.2 E+19$

$2.4 E+18 \quad 4,7 E+14 \quad 3,0 E+15 \quad 2,8 E+14$

$26 \quad 3.2 E+24 \quad 1,1 E+25 \quad 1.3 E+25 \quad 6.1 E+25 \quad 4.4 E+25 \quad 1.4 E+22 \quad 2.5 E+21$

$3.5 E+16 \quad 8,6 E+15 \quad 0.0 E+00 \quad 0.0 E+00$

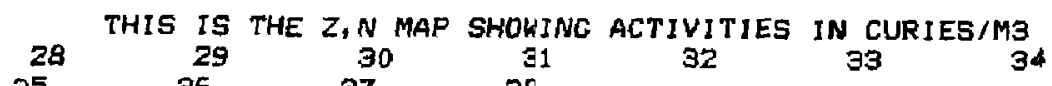

$\begin{array}{ccccccc}35 & 36 & 37 & 38 & & \\ 0 E+00 & 0.0 E+00 & 0.0 E+00 & 0.0 E+00 & 4.4 E-06 & 1.2 E+02 & 0.0 E+00\end{array}$

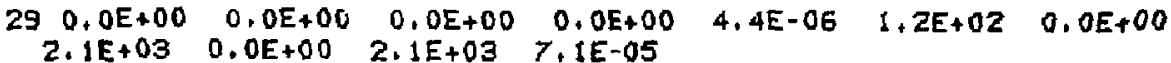

$28 \quad 2.7 E-01 \quad 6.9 E+05 \quad 0.0 E+00 \quad 4,6 E+02 \quad 0.0 E+00 \quad 0.0 E+00 \quad 0.0 E+00$

5. $0 E+04 \quad 0,0 E+00 \quad 2,4 E+05 \quad 2,0 E-01$

$27 \quad 0.0 E+00 \quad 1.3 E+04 \quad 1.3 E+07 \quad 1.0 E+07 \quad 0.0 E+00 \quad 7,2 E+05 \quad 1.0 E+05$

$5,4 E+04 \quad 1,7 E+02 \quad 2,0 E+03 \quad 0,0 E+00$

$26 \quad 0.0 E+00 \quad 2.4 E+06 \quad 0.0 E+00 \quad 0.0 E+00 \quad 0.0 E+00 \quad 6.7 E+04 \quad 4.9 E-03$

1. $8 E+03 \quad 0.0 E+00 \quad 0.0 E+00 \quad 0.0 E+00$

ALPHAS ACCUSULATED $* 4,0 E+03$ (PARTS PER MILLION)

HYDROGEN ACCUMULATED $=1,5 E+04$ (PARTS PER MILLION)

DEUTERIUM ACCUMULATED $=4.0 E+02$ (PARTS PER MILLION)

TRITIUM ACCUMULATED $=1.0 \mathrm{O}+00$ (PARTS PER MILLION)

THE * OF NI TRANSMUTED IS 2.03

IT WAS CHANGED INTO

1. $32 * Z=26$

$0.43 \% Z=27$

$0.01 \times z=29$

Subsequent to this last edit, activity summaries are given for a number of times after the structural component has been removed from the neutron flux. Following are the first three summaries. 
TOTAL ACTIVITY FROM NI AT TIME 1, IE-04 YR AFTER SHUTDOWN IS 2. BE+OP (CI/MB)

THE MAJOR ACTIVITIES ARE:

$1+3 E+07$ (CI/Ma) FOR $Z=27, A=57$

$1.0 E+07$ (C1/Ma) FDR $Z=27, A=58$

$2,4 E+06$ (CI/MB) FOR $Z=26, A=55$

$7+2 E+05$ (CI/MB) FOR $Z=27, A=60$

$6.8 E+05$ (CI/MB) FOR $Z=28, A=57$

TOTAL ACTIVITY FROM NI AT TIME 2.7E-03 YR AFTER SHUTDOWN IS 2 . TE+OF (CI /MB)

THE MAJOR ACTIVITIES ARE:

$2.3 E+07$ (CI/MB) FOR $Z=27, A=57$

1. $O E+07(C I / M 3)$ FOR $Z=27, A=58$

$2.4 E+06$ (CI/MB) FOR $Z=26, A=55$

$7.2 E+05$ (CI/MB) FDR $Z=27, A=60$

4. 4E+OS RCIMAI FOR $Z=28, A=57$

TOTAL ACTIUITY FROM NI A? TIME 1,9E-02 YR AFTER SHUTDOWN IS 2 , GE+07 (CI/MG)

THE MAJOR ACTIVITIES ARE:

$1+3 E+07$ (CI/MB) FOR $Z=27, A=57$

$9.5 E+06$ (CI/MB) FOR $Z=27, A=5 B$

$2.4 E+06$ (CI/MB) FOR $Z=26, A=55$

$7 \cdot 1 E+05$ (CI/MB) FOR $Z=27, A=60$

$6.1 E+04$ (CI/M3) FOR $Z=26, A=59$

Finally, a problem summary is given.

$: 49: 56$

THIS 15 THE END OF THE PROBLEM, IT WAS RUN 10/29/3\% 14

THE NAME OF THIS PROBLEM IS 'NICKEL - MARS FIRST WALL"

THE SDURCE WAS

NI $58 \quad 67.76$ *

NI $60 \quad 26,16 \%$

NI $611.25 \%$

NI $62 \quad 3.66 \%$

NI $64 \quad 1,17 \%$

THE NEUTRON FLUXES WERE 3,57E+00 FAST FLUX, 2,66E+01 SLOW FLUX (1E18 N/MZ-S)

THE CUT-OFF TIME FOR THE FLUXES WAS 5 YR

NUCLEAR DATA WAS TAKEN FROM DISK FILE NIMARFW, LAST UPDATED 09/2 $1 / B 2$

THE Max change allowed in one cycle was $5 *$ 


\section{Conclusions}

The simple and accesible MFE/ACT code has been developed to study long-lived activities from fusion reactors. The code is writen in TRS-BASIC and runs on the TRS-80, Model III. Since it is interactive, with prompts from the computer, it is suitable for users who may not have access to larger operating systems. In addition, all the operating parameters of the fusion reactor, as well as all the nuclear data, are fully accessible for user modification. One data set has been assembled on the basis of the ACTL library maintained by Howerton at Lawrence Livermore National Laboratory. ${ }^{13}$

\section{References}

1. D. I. Dudziak and R. A. Krakowski, "Radioactivity Induced in a Theta-Pinch Fusion Reactor," Nucl. Tech. 25, 32 (1975).

2. Starfire-A Commercial Tokannak Fusion Powut Planl Study, Argonne National Laboratory, Argonne, IL, ANL/FTP-80-1 (1980), vols. 1,2.

3. B. Badger, K. Audenaerde, J. B. Beyer, D. Braun, J. D. Callen, G. A. Emmert. J. M. Gilmore, N. Hoffman, J. Kesner, G. L. Kulcinski, D. C. Larbalestier, E. Larsen, X. Li, W. Maurer, C. W. Maynard, I. Ojalvo, M. Ortman, R. Perry, M. Ragheb, J. Santarius, J. Scharer, D. Schluderberg, K. Shaing, 1. Sviatoslausky, D. K. Sze, W. F. Vogelsang, A. White, P. Wilkes, and T. Yang, WITAMIR-1, A University of Wiscon Tandem Mirror Reactor Design, Fusion Research Program, University of Wisconsin, Madison, WI (1980).

4. G. R. Hopkins et al., The Prospccts of Low Acfivatian Fusion Reactor Design, General Atomic Company, San Diego, CA, GA-A16552 (1981).

5. A. P. Frass and H. Postma, Preliminary Appraisal of the Ha $=$ d Problems of a $D-T$ Fusion Reactor Power Plant, Oak Ridge National Laboratory, Oak Ridge, OR' . TM-2822, Revised (1970).

6. W. F. Vogelsang, "Radioactivity and Associated Problems in Thermonuclear Reactors," Ttchnology of Controlled Nuclear Fusion, U. S. Energy Research and Development Administration, CONF7609350PA (1976), vol. IV, p. 1303.

7. R. W. Conn, T. Y. Sung, and M. A. Abdou, "Comparative Study of Radioactivit; and Afterheat in Several Fusion Reactor Blanket Designs," Nucl. Tech, 26, 391 (1975).

8. R. W. Conn, K. Okula, and A. W. Johnson, "Minimizing Kadioactivity and Other Features of Elemental and Isotopic Tailoring of Materials for Fusion Reactors," Nucl. Tech. 41, 389 (1978).

9. M. 5. Kazimi and R., W. Sawdye, "Radiological Aspects of Fusion Reactor Safety: Risk Constraints in Severe Accidents," 1. Fusion Energy 1 (1981).

10. J. P. Holdren, "Contribution of Activation Products to Fusion Reactor Risk: Part I, a Preliminary Investigation," Nucl. Tech./Fusion 1 (1981).

11. T. Y. Sung and W. F. Vogelsang, DKR: Radioactivity Calculation Code for Fusion Reactors, Nuclear Engineering Department, University of Wisconsin, Madison, WI, UWFDM-170 (1976).

12. 1. A. Blink, FORJG: A Modification of the ORIGEN2 Istope-Generation and Depletion Code for Fusion Problems, Lawrence Livermore National Laboratory, Livermore, CA, UCRL-53263 (1982).

13. M. A. Gardner and R. J. Howerton, ACTL: Evaluated Neutron Activation Cross Section Library-Evaluafion Techniques and Reaction Index, Lawrence Livernore National Laboratory, Livermore, CA, UCRL50400 (1978), vol. 18. In 1979 R. Howerton expanded the ACTL library to allow treatment of fusion reactor structural components.

14. C. M. Lederer, J. M. Hollander, and I. Perlman, Table of Isotopes (Wiley Interscience, New York, NY, 1978), 7th ed. 


\section{Appendix}

10 CLS 'PROCRAM NAME - MFE/ACT

20 CLEAR 1000:POKE 16427, 80

30 DIM IS\$(15), C(5), R\$(5), PA(4)

$40 R+(1)=" Y ": R \$(2)=" D ": R \$(3)=" H ": R \$(4)=" M " ; R \$(5)=" 5 "$

$50 C(1)=1: C\{2\}=2.740 E-3: C(3)=1 .(42 E-4: C(4)=1.9026 E-6: C(5)=3+1709$

$\mathrm{gE}-\mathrm{B}$

60 IS\$ $(3)=$ "WHAT 15 THE ALFHA DECAY HALF LIFE"

70 IS\$ $(4)="$ WHAT IS THE BETA DECAY HALF LIFE"

80 15\$(5) = "WHAT IS THE POSITRON DECAY HALF LIFE"

90 ISt $i \overline{6}$; $=$ "WHAT 15 THE ELECTRON CAPTURE HALF LIFE"

100 1S\$(7)="WHAT IS THE NEUTRON CAPTURE CROSS SECTION FOR "

110 IS $\$(S)=$ "FAST NEUTRONS":IS\$ $(9)=$ "SLOW NEUTRONS" :IS\$ $(11)=$ "DO YO

$U$ WANT TO CHANGE IT (Y/N)"

120 IS\$(IZ)="WHAT IS THE FAST NEUTRON CROSS SECTION FOR "

130 IS\$(13)="N, ALPHA N, N'ALPHA N, N'3ALPHAN, $2 N \quad N, 3 N \quad N$

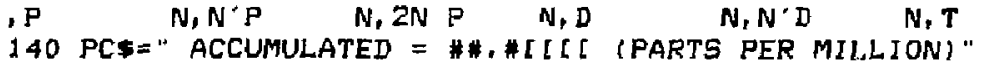

150 PB\$ $=$ "ALPHAS HYDROGEN DEUTERIUMTRITIUM "

160 PRINT: PRINT: PRINT: PRINTTAB 110$)$ "MFE ACTIVATION CALCULATION, D .W. DORN 1982":PRINT:PRINT

170 FOR $I=12$ TO $110: 5 E T(I, 6):$ SET $(I, 13): N E X T$ I:FOR $J=7$ TO $12: 5 E$ $T(12, J):$ SET $(110, J):$ NEXT J

180 PRINT TAB $(10) " * * * * *$ * FUNCTIONS ****** *;:PRI,JT T IME\$: PRINT

190 PRINT TAB(10)"1 SELECT SOURCE"

200 PRINT TAB(10)"2 READ HALF LIFE AND CROSS SECTION DATA FROM

DISK"

210 PRINT TAB 110$)^{\prime 3}$ EN'SEF/CHANGE RADIOACTIVE DECAY DATA"

220 PRINT TAB(10)"4 ENTER/CHANGE NEUTRON CROSS SECTION DATA"

230 PRINT TAB $110, " 5$ SAVE HALF LIFE AND CRDSS SECTIDN DATA ON D1

SK"

240 PRINT TAB 10$)^{\circ 6}$ SET INITIAL PROBLEM CONDITIONS AND RUN PROB LEM"

250 PRINT TAB(10)" 7 MAP DATA FROM ONE DISK FILE TO ANOTHER"

260 PRINT TAB $(10)$ " 8 END SESSION":PRINT

270 INPUT "SELECT DESIRED FUNCTION" ; NOP

280 IF NOP $=1$ AND PD $C>0$ THEN COTO 10

290 IF NOP=1 COTO 400

300 IF $N O P=7$ GOTO 3480

310 IF NOP=B END

320 CLS: IF FF=0 PRINT 9 460, "NEW SESSION, MUST INPUT SOURCE FIR ST

" GOTO 400

330 IF NOF=2 AND PD<>O THEN GOTO 10

340 IF NOP=2 GOTO 580

350 IF NOP=3 GOTO 660

$3 E 0$ IF NOP $=4$ GOTO 940

370 IF NOP=5 COTO 970

380 IF NOP=6 GOTO 1040

390 CLS: PRINT: PRINT:PRINT:PRINT:PRINT:PRINT USING “INCORRECT FUN CTION (*\#)";NOP; : LINE INPUT ", PRESS 〈ENTER〉 TO TRY AGAIN. ";0I\$: CLS:GOTO 180 
400 INPUT "WHAT IS THE MATERIAL YOU WILL BE CALCULATING AND!

15 ITS ATOMIC NUMBER (Z)“;M\$,ZI

410 INPUT "HOW MANY ISOTOPES WILL YOU BE CALCULATING" ; NA

420 DIM A(NA): DIM P(NA)

$430 F O R \quad F=1$ TO NA

440 PRINT"WHAT IS THE MASS NUMBER OF ISOTOPE";F;" AND WHAT 1:

5

450 NEXT $F$

* ABUNDANCE";: INPUT $A(F), P(F)$

460 PRINT"WHAT IS THE AMOUNT OF ";M\$;", IN UNITS OF NUCLEI/M INPUT MA

$470 N(Y=A(N A)-A(1)+1$

$480 \mathrm{JM}=\mathrm{NM}+4$

$490 \mathrm{DIM} N(4, \mathrm{JM}, 68)$

$500 \mathrm{MT}=0$

510 FOR $F=1$ TO NA

$520 \mathrm{~J} \approx A(F)-A(1)+3$

$530 N(3, J, 1)=M A * P(F) * 1 E-Z$

$540 M T=M T+N(3, J, 1)$

550 NEXT $F$

$560 \quad \mathrm{FF}=1$

570 PRINT : CLS: PRINT: GOTO 180

580 INPUT "WHAT IS THE NAME OF THE DISK FILE";NL\$

590 OPEN " I", 1, NL\$

595 INPUT\#1, DA\$

600 FOR $I=1$ TO $4: F O R \quad J=1$ TO JM:FOR $K=3$ TO 21

610 INPUT\#1, N(I,J,K)

620 NEXT K:NEXT JINEXT I

630 CLOSE 1

640 PFINT *

" : CLS: PRINT: GOTO 180

650 REM THIS INPUTS CHANGES TO DECAY

660 FOR $I=I$ TO 4

670 FOR $J=1$ TO JM

680 PRINT"FOR $Z=" ; Z 1+I-3 ; " \quad A={ }^{*} ; A(1)+I+J-6 ;$ : INPUT $Q 3 \$ ;$ IFQ3\$="

OTO 710

690 NEXT J:NEXT I

700 PRINT"

:CLS:PRINT:COTO 180

710 PRINT"FOR THE FOLLOWING DECAY HALF LIVES, INPUT BOTH THE

UE AND THE TIME UNIT, E,G, $1,23,5,1,23, M, 1,23, H, 1,23, D, 1$, $Y, "$

720 FOR L=3 TO 6

730 PRINT "THE VALUE OF "+MID $(I S \$(L), 9)+" 1 S " ; N(I, J, L) ; " Y R . "$

INT "DO YOU WANT TO CHANCE IT (Y/N)"; INPUT Q75

740 IF $Q 7 \$\langle\rangle " Y "$ GOTO 800

750 PRINT IS\$(L); : INPUT N(I,J,L), L\$

$760 \mathrm{FOR} K=1$ TO 5

770 IF $L *=R *(K) \quad N(1, J, L)=N(I, J, L) * C(K):$ COTO 300

780 NEXT $K$

790 PRINT"INCORRECT TIME UNIT, PLEASE TRY AGAIN! ":COTO 750

800. NEXT L

B10 NEXT J NEXT I

820 PRINT "

: CLS: PRINT: COTO 180

890 REM THIS INPUTS CHANGES TO NEUTRON CROSS SECTIONS 
R40 FOR $I=1$ TO $4: F O R \quad J=1$ TO JM

B50 PRINT"FOR $Z=" ; Z 1+I-3 ; " A=" ; A(1)+1+J-6 ;$ : INPUT GS5: IF GSW="r COSUB BBO ; RETURN

860 NEXT J:NEXT I

B70 PRINT “

":CLS: PRINT : COTO 180

B80 FOR $L=18$ TO 19

890 PRINT MID\$(I5\$(7),9)+15\$(L-10):PRINT " IS";N(I,J,L);" BARNS, "+IS\$(11);: INPUT Q7\$:IF Q7\$="Y" PRINT IS\$(7)+IS\$(L-10); : INPU" N(I,J,L)

900 NEXT L

910 PRINT

$+\operatorname{MID} \$(1 S \$(7), 9,4)+\operatorname{LEFT} \$(15 \$(9), 12)+M(D \$(I S \$(7), 2 \beta)$

+MID\$(IS\$ $(13), 51,3)+" I S^{\prime \prime}$ N $(I, J, 20)$; "BARNS, "+IS\$(1); : INPUT $Q>\$$

IIF $Q 7 \$=" Y "$ PRINT LEFT\$(IS\$(7), 12)+LEFT\$(IS\$ $(9), 12)+M I D S(1 S \$(7)$, $28)+M I D(150(13), 51,3)$; : INPUT N $(I, J, 20)$

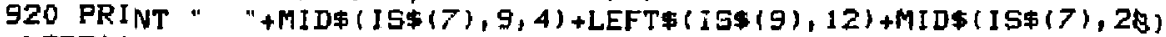
+LEFT $(I S \$(13), 7)+"$ IS"; N $(I, J, 21)$; BARNS, "IS\$(11);:INPUT Q7\$ 1 $F$ G $\$=" Y "$ PRINT LEFT\$(IS\$(7),12)+LEFT\$(15\$(9), 12)+MID\$(IS\$(7), Z8 $1+$ LEFT\$ $(15 \$(13), 7) ;:$ INPUT N $(I, J, 21)$

930 FOR $L=0$ TO 10

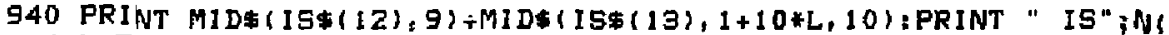

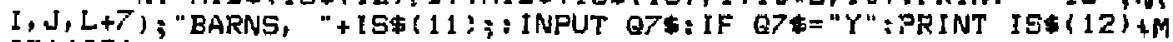
ID\$(IS\$ (13), 1+10*L, 10);: INPUT $N(I, J, L+7)$

950 NEXT L

960 RETURN

970 INFUT "WHAT DO YOU WANT TO CALL THE NEW DATA FILE" ;NL\$

980 OPEN "O", 1, NL\$

985 DA\$ =LEFT $\$$ (TIME $\$, 8)$

986 PRINT*1, DAF

990 FOR I=1 TO $4:$ FOR $J=1$ TO JM:FOR $K=3$ TO 21

1000 PRINTH $1, N(I, J, K)$;

1010 NEXT K:NEXT J:NEXT I

1020 CLDSE 1

1030 PRINT :

$"$ : CLS: PRINT : COTO 180

1040 INPUT "WHAT IS THE NAME OF THIS PROBLEM"; NM\$: PRINT

1050 INPUT "WHAT ARE FLUXES FOR THE FAST AND GLOW NEUTRONS IUNYT 5 OF IE18 N/MZ-SEC) ";F1, P2: INPUT "WHAT IS THE CUTOFF TIME FOR TH E FLUXES (YR)"; TF

JOED JNPLT "WHAT PERCFATACE CHANGE WILL YOU ALLOW FOR AN ISCTOFE IN ONE TIME STEP";DT

$1070 \mathrm{DT}=\mathrm{DT} / 100$

1080 INPUT "HOW FREQUENTLY DO YOU WANT AN EDIT (YR)";ED

10 OS FOR $K=1$ TC 4:PA(K)=0: NEXT $K$

1100 FOR $I=1$ TO 4 : FOR $J=1$ TO JM

$1105 N(I, J, 68)=1$

1110 FOR $K=7$ TO 18

$(120 N(I, J, K+15)=P I * N(I, J, K) * 3,154 E-3$

1130 NEXT K

1140 FOR $K=1$ TO $3: N(I, J, K+33)=P 2 * N(I, J, K+18) * 3,154 E-3$

$1150 \mathrm{NEXT} \mathrm{K}$

1160 FOR $K=3$ TO 6

1170 ON ERROR GOTO 1200

$1180 N(I, J, K+34)=0,6931472 / N(I, J, K)$ 


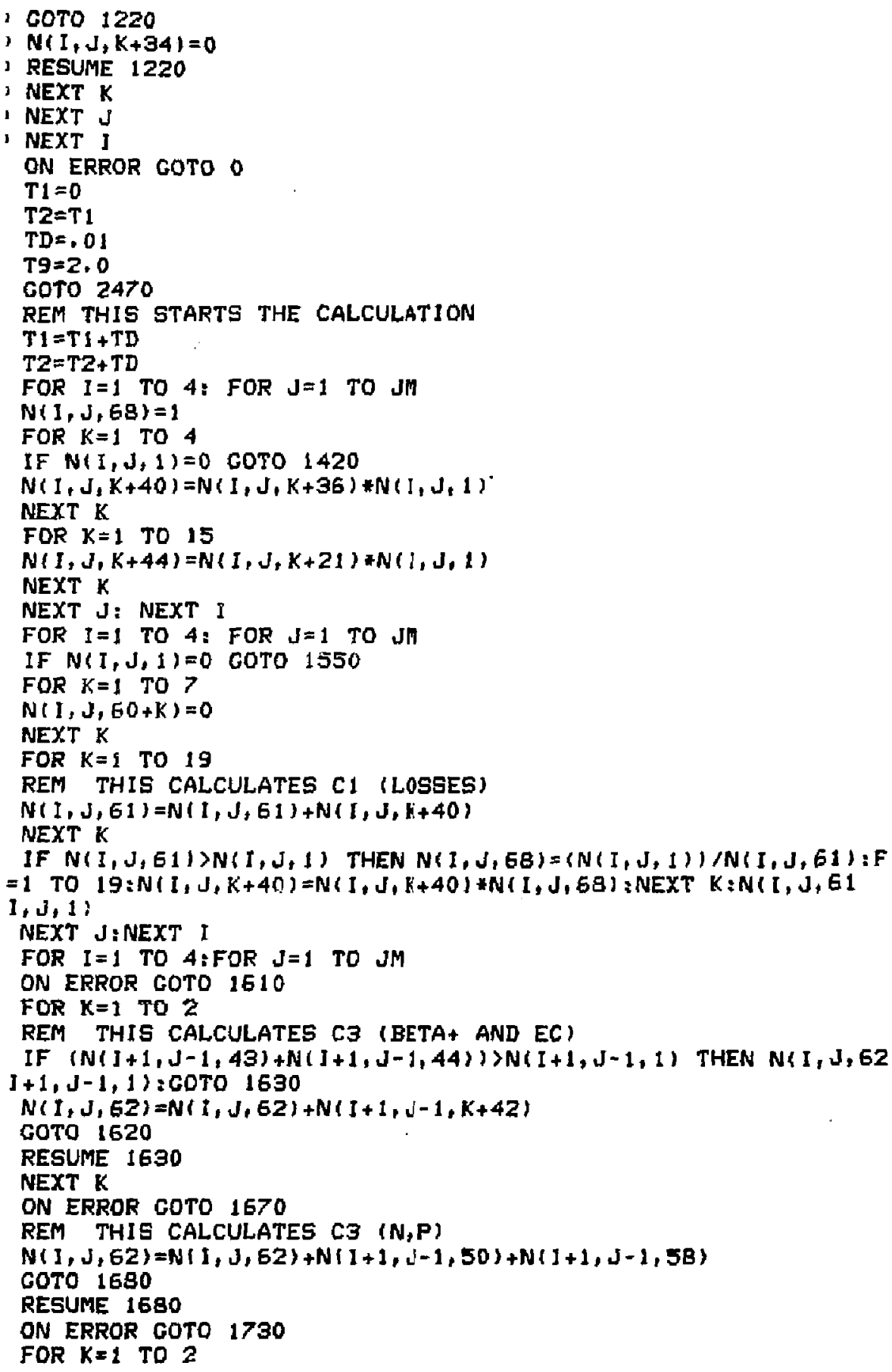




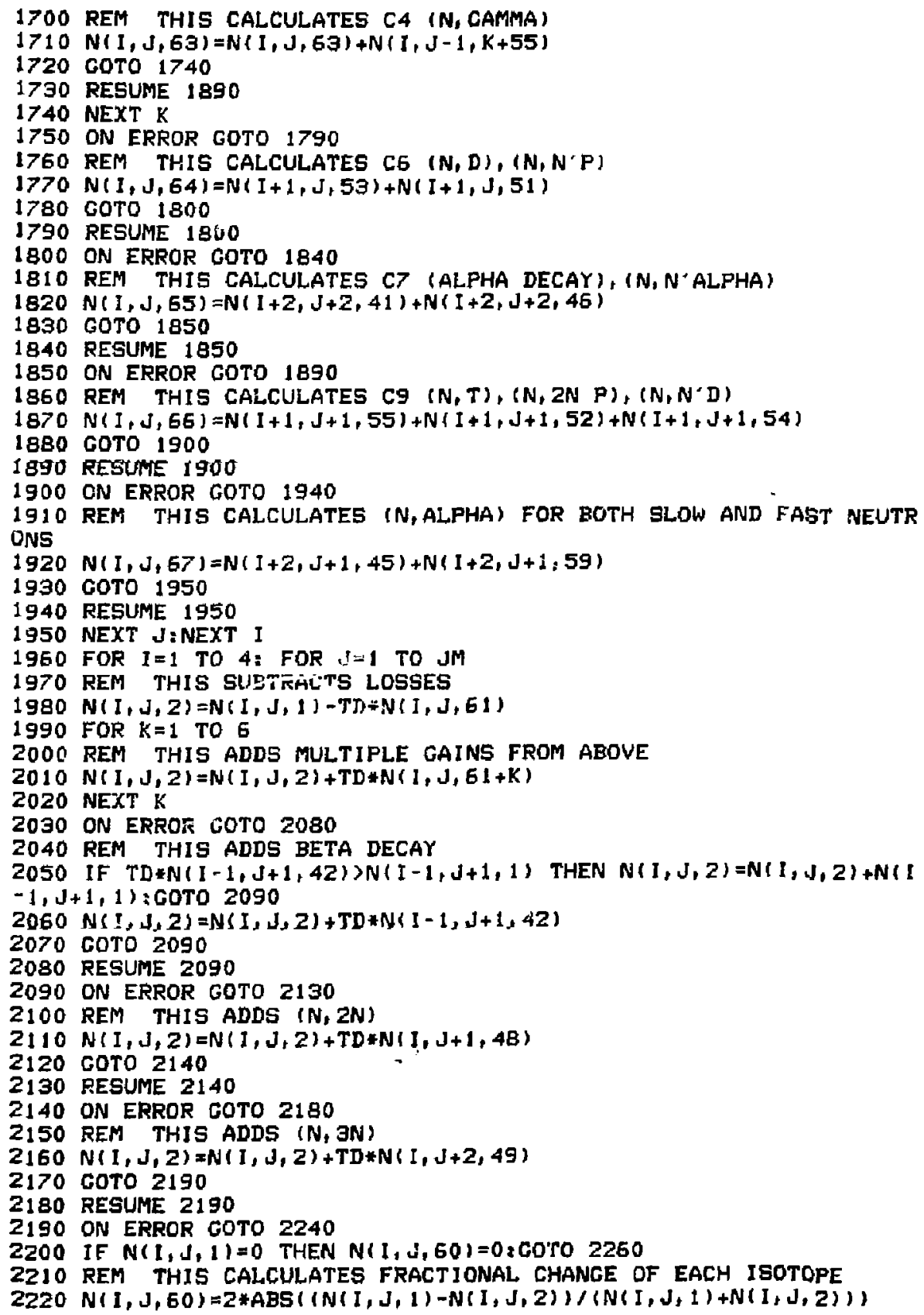




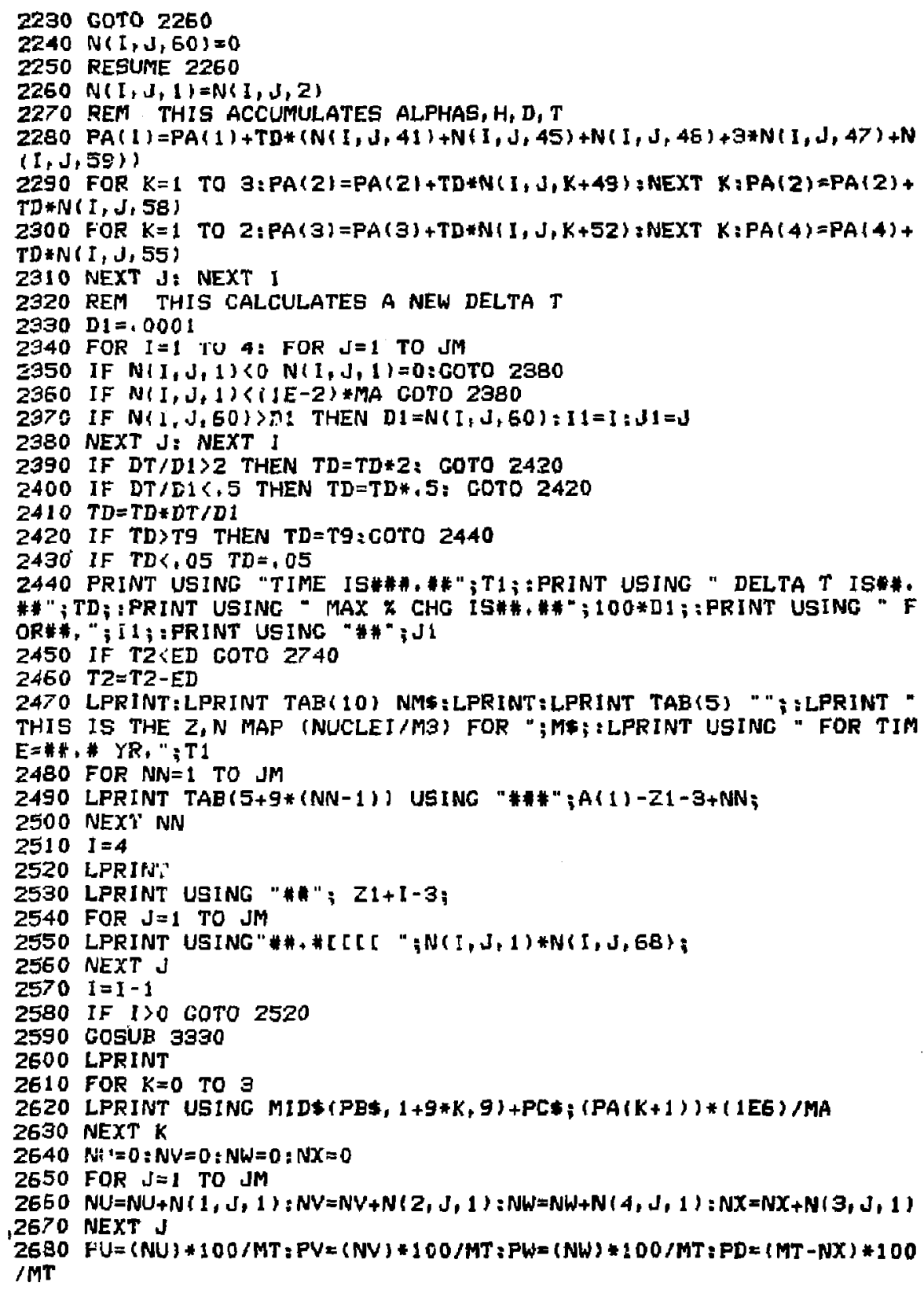


2690 LPRINT "THE * OF ";M*;:LPRINT USING " TRANSMUTED ISH" *"*"

PD

2700 LPRINT "IT WAS CHANCED INTO"

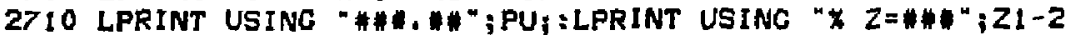

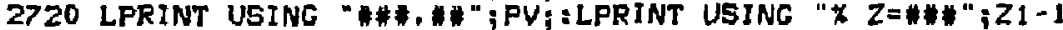

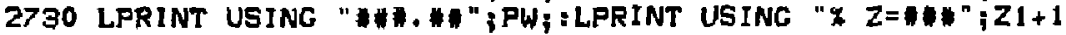

2740 IF $(T 2+T D)>E D$ THEN TD=ED-T2+.001

2750 IF TI TTF COTO 1320

2760 ON ERROR GOTO 0 :DIM T(13), MA(E), NI(6), NJ (6)

$2770 T(1)=1,1416 E-4: T(2)=2.7397 E-3: T(3)=1,9231 E-2: T(4)=B+2192 E-2$

$: T(5)=1: T(6)=5: T(7)=10: T(g)=20: T(9)=50: T(10)=100: T(11)=500: T(12)$

$=1000: \mathrm{T}(13)=10000: \mathrm{K}=0$

$2780 K=K+1: N T=0: F O R$ I=1 TO 4:FOR $J=1$ TO JMINL=0:FOR $L=1$ TO $4: N L=$ $N L+N(I, J, L+36): N E X T \quad L: N(I, J, 2)=N(I, J, 1) * N(I, J, 68) * E X P(-T(K) \neq N L)$

2750 FOR $N=1$ TO 5: IF $N(I, J, 2)$ *NL/1,17EI8)NA(N) THEN NP=N(I,J,2: * NL/1.17E18:IP =I:JP=J:GOTO 2820

2800 NEXT $N$

2810 GOTO 2860

2820 FOR $M=6$ TO $N+1$ STEP -1

$2830 N A(M)=N A(M-1): N[(M)=N I(M-1): N J(M)=N \cdot](M-1)$

2840 NEXT M

$2850 N A(N)=N P: N I(N)=I P: N J(N)=J P$

$2860 N T=N T+N\{I, J, Z\} * N L / 1,17 E 18$

2870 NEXT J:NEXT I

2880 LPRINT:LPRINT:LPRINT "TOTAL ACTIVITY FROM " IM\$ ILPRINT USIN

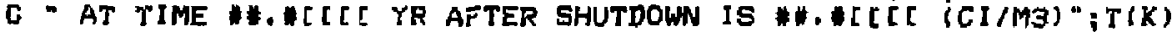

; NT

2890 LPRINT "THE MAJOR ACTIVITIES ARE:"

2900 FOR $R=1$ TO 5

2910 LPR INT USINC "*\#. \#[ $t[$ (CI/MG)"; NA(R) i I IF NA(R)>0 THEN LPRI

NT USING "FOR $Z=\|*, A=*\| * ; Z 1+N I(R)-3 ; A(1)+N I(R)+N J(R)-6$

2920 IF $N A(R)=0$ THEN GOTO 2950

$2930 \mathrm{~N}\{\mathrm{i}\{\mathrm{R}\}=0$

2940 NEXT R

2950 IF $\mathrm{K}<13$ GOTO 2780

2960 LPRINT:LPRINT:LPRINT TAB 10 10"THIS IS THE END OF THE PROBLEM - IT WAS RUN "; TIME\$

2970 LPRINT:LPRINT "THE NAME OF THIS PROBLEM IS ";NM\$;" *

2980 LPRINT :LPRINT "THE SOURCE WAS"

2990 FOR I=1 TO NA:LPRINT M\$;

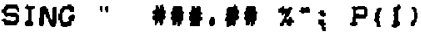

3000 NEXT I

3010 LPRINT USING "THE NEUTRON FLUXES WERE H\#\#ICCt FAST FLUX,

**, **C[E[ SLOW FLUX" ; $P_{1}, P 2 ;$ iLPRINT " (IEIB N/M2-S)"

3020 LPRINT USING "THE CUT-OFF TIME FOR THE FLUXES WAS H* YR*;T $\mathbf{F}$

3030 LPRINT "NUCLEAR DATA WAS TAKEN FROM DISK FILE ";NL\$;", LAST UPDATED " DAF

3040 LPRINT "THE MAX CHANGE ALLOHED IM ONE CYCLE WAS "; 100*DT; " $x$

$3050 \quad F F=1$

3060 INPUT "DO YOU WANT TO DUTP!JT THE DECAY AND NEUTRDN CROSS SE CTION DATA FOR EACH OF THE ISOTOPES CONSIDERED (Y/N)";GI

3070 IF $O 1 \$=" Y "$ GOTO 3090

3080 COTO 3290 


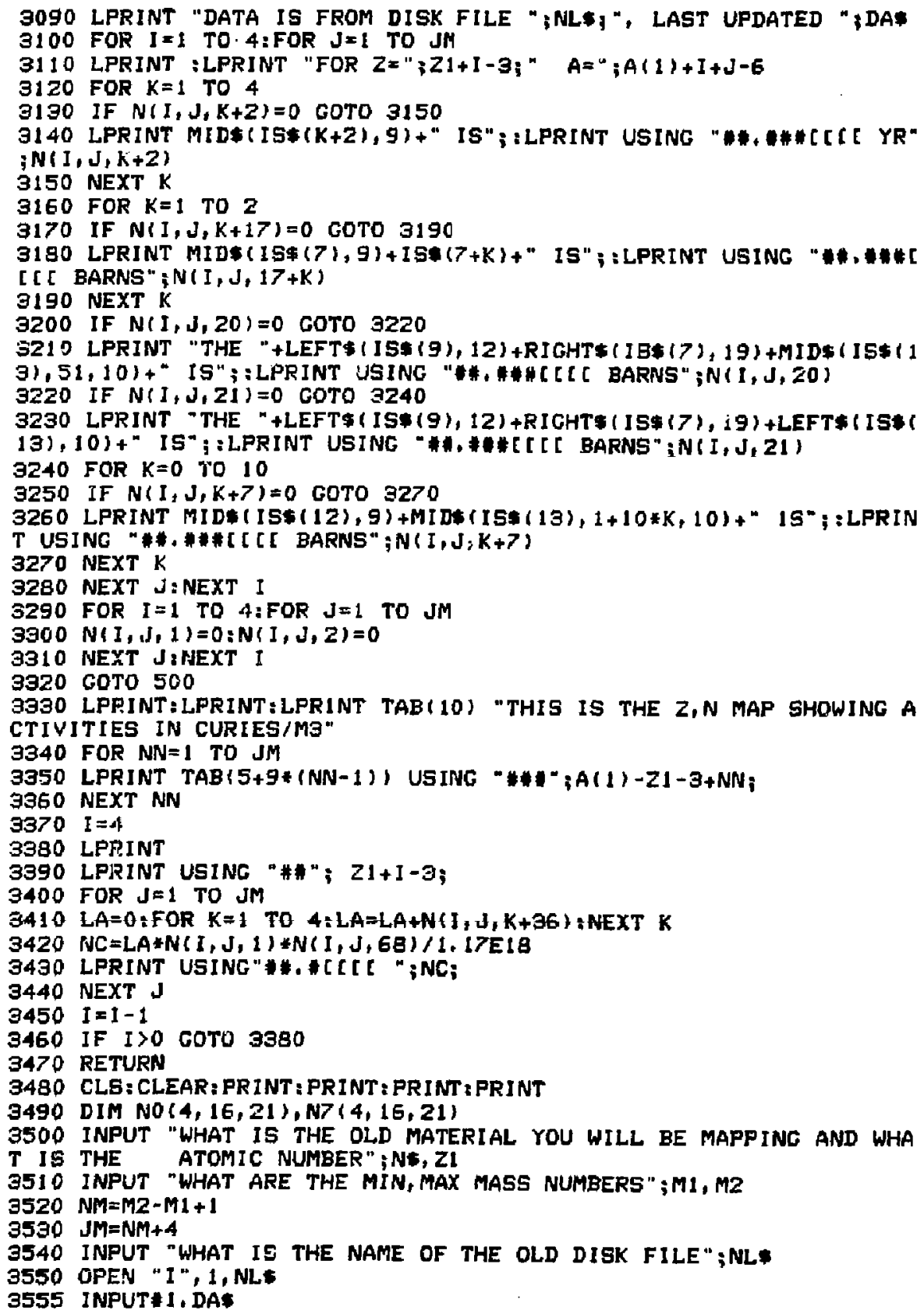


3560 FOR $I=1$ TO $4: F O R \quad J=1$ TO $J M: F O R \quad K=3$ TO 21

3570 INPUT: $1, N O(I, J, K)$

35BO NEXT K:NEXT J:NEXT I

3590 CLOSE 1

3600 IF FL $=1$ COTO 3660

3610 INPUT "WHAT IS THE NEW MATERIAL YOU WILL BE MAPPING INTO AN D WHAT IS ITS ATOMIC NUMBER"; M\$, 22

3620 INPUT "WHAT ARE THE MIN, MAX MASS NUMBER5" ; N1, N2

$3630 \quad N N=N 2-N 1+1$

$3640 \quad J N=N N+4$

3650 IF ABS $(Z 1-Z 2)>3$ PRINT "THERE IS NO MATCH FOR MAPPING DATA":

GoTo 9540

3660 IP=Z1-ZZ:Q=N1-ZZ-M1+Z1

3670 FOR $I=1$ TO 4:FOR $J=1$ TO $J N=F O R \quad K=3$ TO 21

3680 IF I-IP $>4$ OR I-IP〈I OR $Q+J\rangle M 2-M 1+5$ OR $Q+J\langle 1$ THEN GOTO 3730

3690 IF $N O(I-I P, J+Q, K)=0$ COTO 3730

$3700 N 7(I, J, K)=N O(I-I P, J+Q, K)$

3730 NEXT K: NEXT J:NEXT I

3740 INPUT "MAPFING DONE. DO YOU WANT TO SAVE IT ON DISK";Q1"

3750 ON ERROR COTO O

3760 IF QI* "Y" GOTO 3790

3770 INPUT "DO YOU WANT TO CONTINUE";02\$:IF Q2\$="N" COTO 10

$3780 \mathrm{FL}=1$ : GOTO 3500

3790 INPUT "WHAT DO YOU WANT TO CALL THE NEW DATA FILE" ;NW:

3800 OPEN "O", 1, NN

3BDS DAS=LEFT $\$$ (TIME\$, Q)

3Q06 PRINTE 1, DA:

3810 FOR $I=1$ TO $4: F O R \quad J=1$ TO JM:FOR $K=3$ TO 21

3920 PRINT:L, NT (I,,$K)$;

3830 NEXT K:NEXT J:NEXT I

3840 CLOSE 1: INPUT "DO YOU WANT TO DO MORE MAPPING"; 1 "

3Q50 IF $Q 1 \$=" Y *$ THEN FOR $I=1$ TO $4: F D R \quad J=1$ TO JN;FOR $K=3$ TO $21: N 7$ $(I, J, K)=0: N E X T$ K:NEXT JiNEXT I :FL=0:GOTO 3480

3960 GOTO 10 